\title{
SIMPLE INTEGRATION OF SENSORY FUNCTIONS
}

\author{
Vogel, Sven; Kirchner, Eckhardt \\ Technical University Darmstadt
}

\begin{abstract}
The digitalization of the Industry is one of the megatrends taking place, but many companies struggle to follow this trend. The main reason is the absence of simple solutions for the integration of sensory functions, which are applicable to the existing system. Therefore, this paper discusses the aspects of simplicity in the context of integrating sensory functions into existing systems, to support the development of digitalized products.

Two general requirements can be formulated for a solution to be applicable simple: The first requirement is affected by the product structure. The solution must affect the least possible amount of modules and must not interfere with the interfaces of the modular platform. The second requirement is affected by the effort to model the behaviour of the desired information and the possible data a sensory function is delivering. The effort to develop a reliable solution has to be compared with the commercial potential of the solution.

To consider the mentioned requirements, the paper explains three approaches to assess the simplicity of solutions on an example of the desired monitoring of the functions of a rotary plug valve.
\end{abstract}

Keywords: Product modelling / models, Product architecture, Functional modelling, Simplicity, Sensor integration

\section{Contact:}

Vogel, Sven

Technical University Darmstadt

Product development and machine elements

Germany

vogel@pmd.tu-darmstadt.de 


\section{INTRODUCTION}

The reasons for the need of sensory functions vary from the megatrend of digitalization of the industrial manufacturing processes also known as Industrie4.0 and Industrial IoT, over safety features or new requirements for example in the actuators of robots interacting with humans or to validate assumptions made during the product development. All these reasons lead to different requirements for a sensory function. The authors experience with company representatives is that the common requirement across different companies is the need for a simple solution.

Current solutions to support the digitalization by a simple integration of sensory functions into existing system are derived from academia and are partly technology driven with a search for a widespread application. They are based on adding a sensory function to the traditional, normally mechanical function of standardized components. Examples are shown in (Schork et al., 2016) where couplings are equipped with sensors to measure the transferred torque and the eccentricity of the shaft, in (Groche and Brenneis, 2014) and (Brecher et al., 2016) where sensors are introduced into a bolt to measure the reaction force on a machine and even in some already available products like FAG VarioSense ${ }^{\circledR}$ (Schaeffler Technologies AG \& Co. KG, 2017)

All the mentioned solutions were developed to simplify the integration of sensory functions into already existing systems. Simplicity though is multidimensional and depends among other facts on the boundary conditions, the expectation of the user and the purpose of the product, as a workshop during the DESIGN2018 also concluded. Not taking the boundary conditions of the user into account risks the usability of a solution.

Therefore, this paper presents an approach that is taking the individual boundary conditions for a simple integration of sensory functions into existing systems into account. The aim is to gather the most value information by keeping the effort for the integration low.

\section{BACKGROUND}

This chapter summarizes assessments to identify the individual boundary conditions and considers the system knowledge. The assessment shall lead to a decision that is based on a better knowledge about the relations of the existing system. Therefore assumptions are made and explained in the next sections.

\subsection{Existing systems}

This papers aims to support the integration of sensory functions into existing systems. Mostly developments are based on existing systems that are experiencing new requirements. Therefore the systems is partly further developed to fit the new requirement. The target is to further develop the smallest part of the existing system and to keep as many as possible parts, to keep the overall development effort as low as possible. An existing system can be an already manufactured entity, for example a factory, a machine inside a factory, a drive system of a machine or even a part of the drive system. An existing system can also be an existing modular platform, which also is a product, from which other products are customized and produced. This understanding is important, because for nonexisting systems that are designed newly from scratch, the new requirements are taken into account anyway. As soon the product exists, in physical or non-physical form, a new requirement leads to changes of the existing system that should take place by keeping as many parts as possible. Otherwise it leads to high effort in redesign.

\subsection{Modular products}

Many products are developed and manufactured in a modular way because of different modular drivers (Krause and Gebhardt, 2018). To fulfil the requirements of modularity the interfaces are standardized enabling the combination and exchange of the components. In this understanding a product that is made of modules can be a module of a higher level system itself - Shown in Figure 1. Even software is a module that is often the objective of further development and exchanged by software updates. Modular drivers can be, amongst others the demand for exchange due to wear, the customization, or the possibility to react to future requirements by further developing only components of the product and keep as many parts as possible (Greve and Krause, 2018). Because the modular 
platform are mostly the result of extensive optimisation based on the business model of the company, changes to parts or the modular platform are often limited.

Therefore, a simple way for the integration of sensory functions has to take the boundary conditions given by the modular platform and the modular drivers into account.

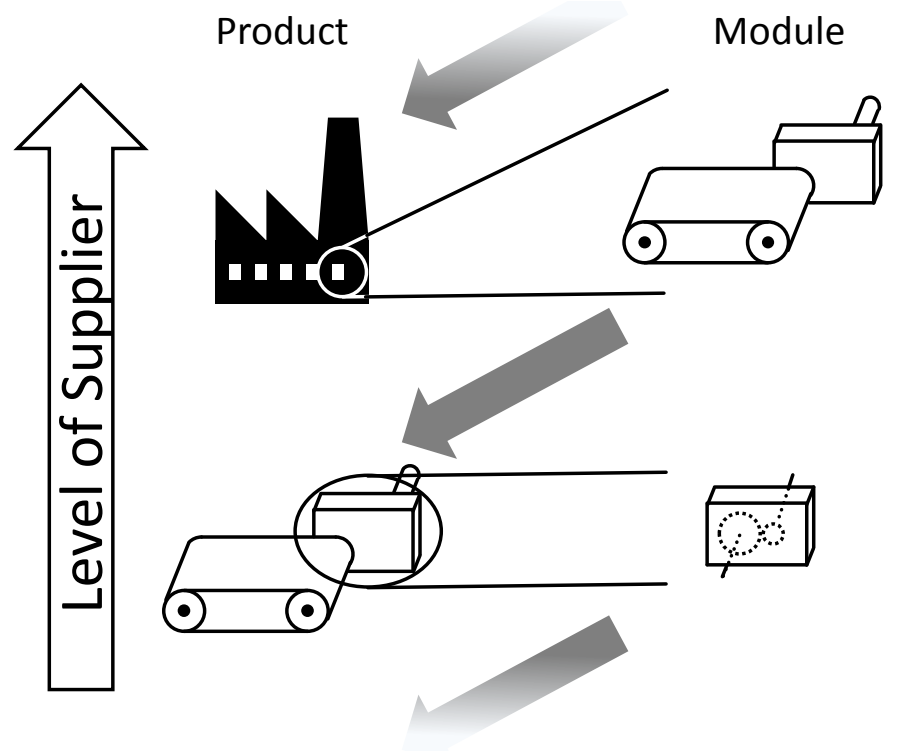

Figure 1: Products are modules of higher-level systems.

\subsection{Accuracy vs. modelling effort}

Models are the basis for aggregation of data to information. The purpose of the model defines the necessary accuracy of the information resulting from the aggregation of data by the model (Stachowiak, 1973). Because a model maps the real relation between the data and the information by simplification the relation due to the desired accuracy, a more accurate model requires more effort in describing the relation between the data and the information and more data has to be taken into account. Parameter that are not taken into account, because of missing knowledge or reduced requirements for the accuracy are called disturbances. The desired accuracy of a model and the modelling effort thus are contrary, but both are depended on the disturbances that have to be taken into account. Therefore, the possible disturbances are a measure for both, the accuracy of the model and the modelling effort. In this paper is assumed, that the necessary accuracy is defined by the requirements for the sensory functions and therefore solutions will be compared by means of effort to consider the disturbances and validate the model.

\subsection{Interims conclusion}

As a result of the previous sections, the integration of a sensory function is achieved by further developing a module of the system and exchanging the previous module. This can be done by exchanging a machine with a newer machine that offers the new sensory function for the higher level system, by exchanging a single part of the machine that is offering a sensory function or by placing a sensory device on part of the machine, which can be considered as a further development of this part. The requirements for a simple solution differ for every company, because the boundary conditions regarding modular platform, business model and modelling capacity vary. In (Martin et al., 2018) requirements for a simple integration of sensory functions are already generally formulated:

- A known and robust transmission of the sensor signal - this is equivalent to the formulation of the requirement of keeping the modelling effort low.

- Standardized interfaces of the sensory device - this is equivalent to the formulation of the requirement of keeping the changes of the modular platform low.

- Simple solution for the tools of handling the sensory device - this is also considered in the requirement of keeping the changes of the modular platform low.

This paper formulates the aspects of a simple solution for the integration of a sensory function into an existing systems are on the one hand low effort in modelling the behaviour and on the other hand low 
changes to the existing modular platform that includes the existing space and interface of the further developed part.

The listed aspects seem to be trivial, but have a high influence on the simplest solution, which shall be displayed by the following examples of current trends. Mass produced or mas customized products like cars are often based on modular platforms to offer a high variability of the products. The additional costs of integrating additional sensory devices into the system to monitor components cannot be justified, so efforts are made to develop models to gather the desired information of existing data (Foulard et al., 2015). The module that can be exchanged the simplest way, in this case is the software, because no changes are influencing the packaging and the further developed module can be used in almost every variant being produced.

The other spectrum of the current trend is the development and integration of individual sensory devices, because modelling all the influences is not justified. These products are normally produced only once or a few times, for example bridges as shown in (Zhou et al., 2016). The products normally have a long usage phase, are investment-intensive and a sufficient modularity for exchanging modules is not given. The costs and the long amortization period prevent a new development of the system. Therefore, the development and the effort in developing sensory devices and the corresponding models is justified and a lot of research is done under the key word structural health monitoring.

Between these extrema are products being built with a decent modularity to fit the customer needs, but the effort to model the relation of the data already existing, or being gathered from an outside placed sensory device is not justifiable (Groche et al., 2015) showed on a machine for a roll forming process. The restriction given by the modular structure, the interfaces and the packaging of such products have led to the development of many individual solutions shown in the introduction.

A general approach to support companies in developing or identifying potential exchangeable further developed modules might simplify the integration of sensory functions into the existing systems and thereby support the digitalization of the industry.

\section{EXPLANATION OF THE BOUNDARY CONDITIONS OF THE EXAMPLE}

For better understanding, the approach shall be explained using an example. The example is a rotary plug valve as shown on the left hand side in Figure 3. This product is used in chemical plants and has two different operating modes. The first is used to control the volume flow of a fluid, for example hot steam to control the temperature of a reaction process or a highly dangerous fluid. The second is used to close the valve to stop the volume flow, for example in a case of emergency or maintenance.

In this paper, the safety critical function of closing the valve that has to be guaranteed in all situations is focused. An extract of the product structure is shown on the right hand side in Figure 3. By varying the modules, the product can be adjusted to the customer needs, while keeping the production costs low. The modular platform is important for the company, because it enables a quick and simple assembly for individualized products, and is the result of the company's experience and expertise. The manufacturer desires two different information, called the target information. The first desired information is the torque acting on the shaft, to prevent an overload of the shaft that leads to deformation and limited usability or even breakage of the shaft and a total loss of function. The second desired information is if an unforeseen body inside the process media blocks the valve. The product structure has to be kept, otherwise the changes of the product structure risk the profitability of the business model.

\section{APPROACH TO SUPPORT THE DECISION OF INTEGRATING SENSORY FUNCTIONS INTO EXISTING SYSTEMS}

The author assumes a simple integration is pushing the industrial digitalization. Therefore, in this and the following chapters, the requirements for an integration of sensory functions, to be simple and assessments to consider these boundary conditions, are presented. A general overview of the presented ideas and their relations are shown in Figure 2. 


\section{Target}

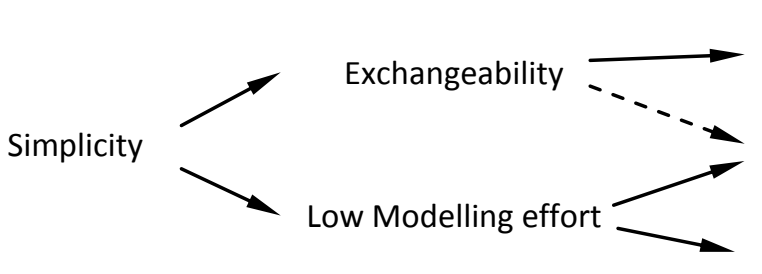

Evaluated by

Effect

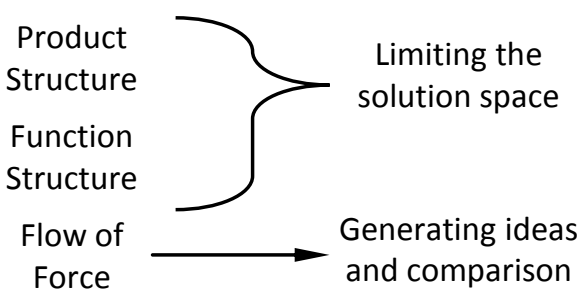

Figure 2: General overview of the presented ideas and their relations.

The approach is based on limiting the solution space as early as possible. The assumption is that the simplest solution lead to no changes in the rest of the system. Sometimes these solutions are called plug and play, because after installation of the new part no further work need to be done. By taking the product structure into account, the properties of the modules are compared to reduce the solution space for the next step. The second step uses the function structure to estimate the effort of modelling the relation between measurable quantities and target quantities. The third step uses the flow of energy evaluated with the working space model to identify possible disturbances and give a first analytical model for the relation of the target quantity and the identified measureable quantity.

\subsection{Product structure as basis for reduction of the solution space}

In Figure 4 the components that are important and have to be taken into account for the possible integration of a sensory function, to gather the desired information, are shown. The basis for the integration for the sensory function is the exchange, which includes further development, of parts. To guaranty a high benefit from the least effort, modules that are part of the most sold variant and show less variety in their appearance then others. A first approach was presented in (Vogel et al., 2018). Further research has shown modular variety and effort to model the influences have to be taken into account separately. In this example, the product structure is taken into account by listing the advantages and disadvantages, shown in Table 1.

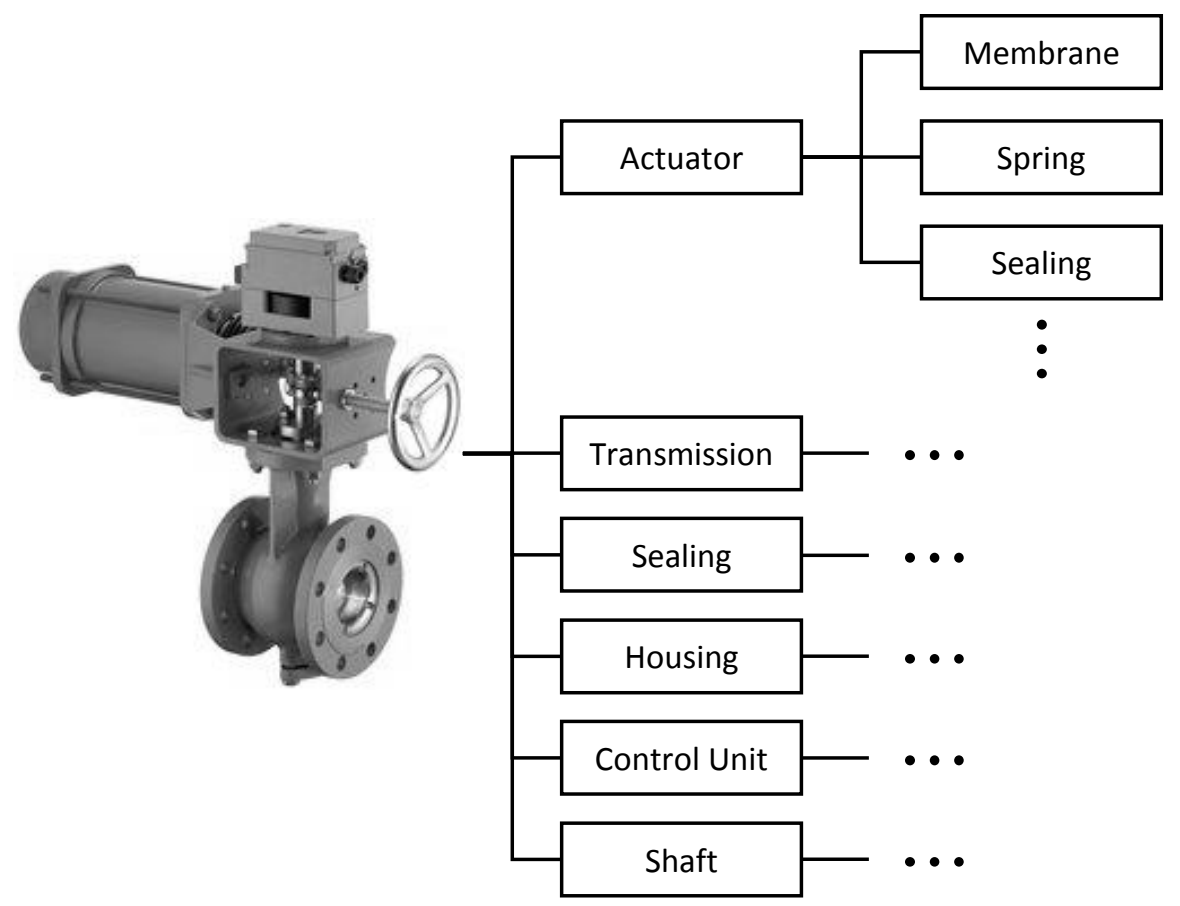

Figure 3: Left: Example of rotary plug valve; right: Part of the product structure of the rotary plug valve. 
Table 1: Advantages and disadvantages for exchanging the module

\begin{tabular}{|l|c|c|r|}
\hline Component & \multicolumn{1}{|c|}{ Advantages } & Disadvantages & Potential \\
\hline Bealing (Seat, & $\begin{array}{c}\text { Seat and body are directly } \\
\text { experience the target value. } \\
\text { Needed in every product. }\end{array}$ & $\begin{array}{c}\text { Very high variety of components, } \\
\text { because of dependency to the } \\
\text { process media }\end{array}$ & No \\
\hline Bearing & $\begin{array}{c}\text { Experience reaction force of } \\
\text { sealing force } \\
\text { Manufactured in-house. }\end{array}$ & $\begin{array}{c}\text { Exposed to process media. } \\
\text { Medium variety of material. } \\
\text { Size depended on size of valve }\end{array}$ & No \\
\hline Housing & $\begin{array}{c}\text { Needed in every product. } \\
\text { Variety of different materials to } \\
\text { fit the process media. }\end{array}$ & Yes \\
\hline Shaft & $\begin{array}{c}\text { Manufactured in-house } \\
\text { Space for Changing the design } \\
\text { The component desired to be } \\
\text { monitored. }\end{array}$ & $\begin{array}{c}\text { Diameter depends on the size of } \\
\text { the valve }\end{array}$ & Yes \\
& $\begin{array}{c}\text { Manufactured in-house } \\
\text { Not exposed to process media. }\end{array}$ & $\begin{array}{c}\text { Medium variety of designs } \\
\text { Size depends on the size of the } \\
\text { valve }\end{array}$ & No \\
\hline Actuator & $\begin{array}{c}\text { Not exposed to process media. } \\
\text { Space for Changing the design }\end{array}$ & $\begin{array}{c}\text { Completely purchased part. } \\
\text { Medium variety of designs. } \\
\text { Size depends on the Size }\end{array}$ & Yes \\
\hline
\end{tabular}

The results of the assessment shown in Table 1 is highly subjective to the belief and the experience of the individual listing and assessing the advantages and disadvantages, but already deliver a basis for discussion about which components are worth to take into account when considering further develop a component. Because the aim is a simple solution for integrating a sensory function, the assessment needs an expert of the considered product family, to evaluate the simplicity of exchanging a component. In the example the components worth being considered are Housing, Shaft and Actuator. Bearing and sealing are too difficult to further develop, because they are already the lifetime dominating parts because of degradation during use and changes risk the current performance of the products. The transmission is also not taken into account, because too many products are sold without transmission, risking the use of the further developed component in sufficient variants. The Housing, Shaft and Actuator are taken into account, because they are used in most products. The housing, as a containment for the dangerous process media is critical to safety, but all sensor principle that are not weakening the structure can still be considered. The Shaft is being considered, because this component is manufactured in-house and the current embodiment design offers a wide solution space of further development.

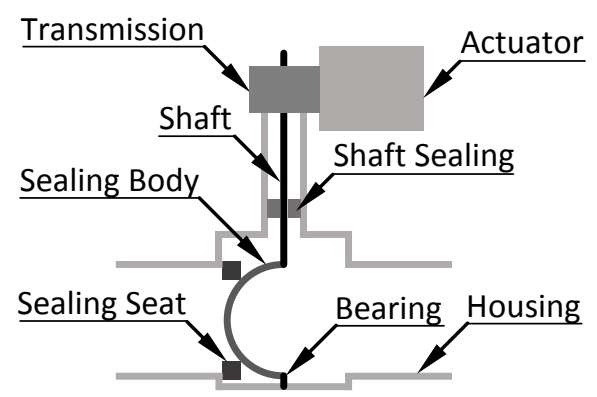

Figure 4: Components for possible integration of a sensory function.

\subsection{Process model as basis for first evaluation of necessary modelling effort}

In Figure 5 the function structure for shutting down the flow of the process media, based on (Pahl et al., 2007) and the general functions with the general values defined in (Roth, 2000), is shown. 


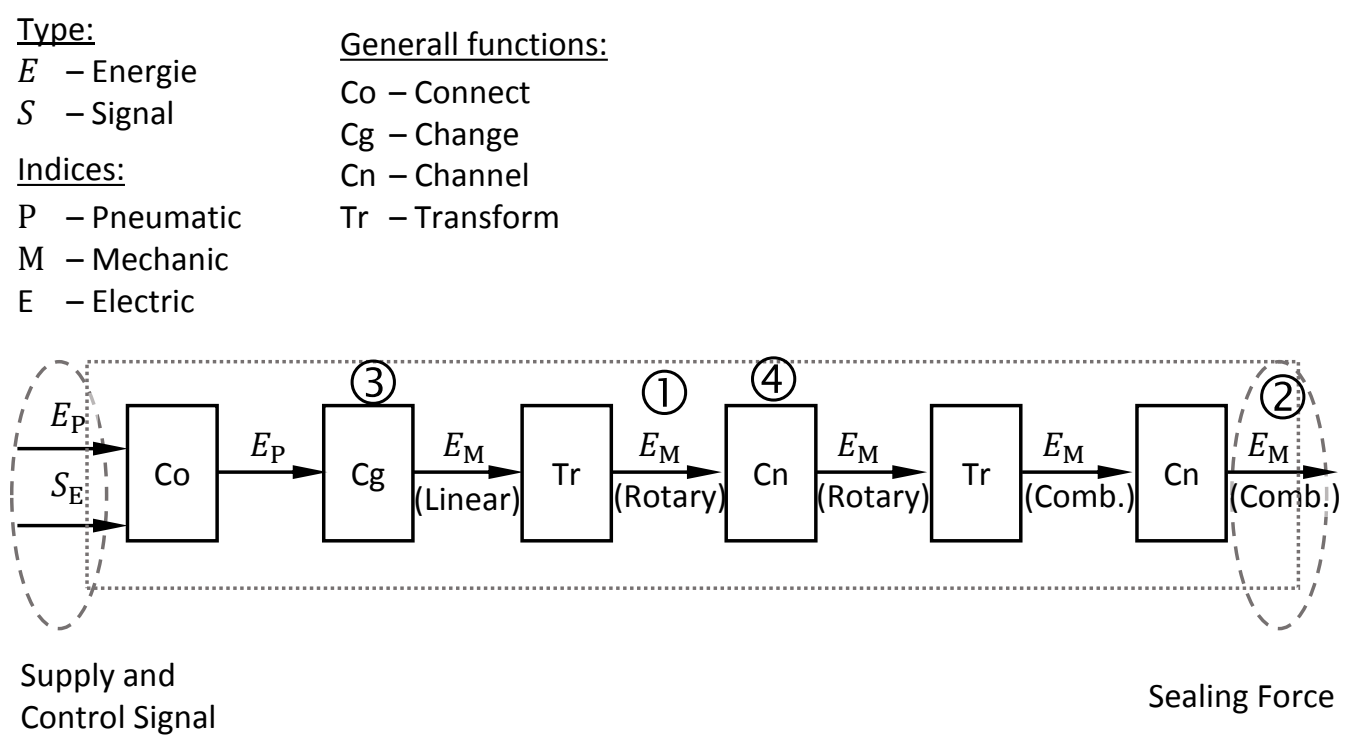

Figure 5: Function structure of the rotary plug valve delivering the sealing force.

The target information if the shaft is exposed to an overload can be derived from the torque acting on the interface - target quantity one - between transmission or actuator and the shaft. In the function structure of channelling the energy from the supply to the sealing force, the target quantity for this desired information is represented as (1) in Figure 5. The second target information if the valve is blocked can be derived from the sealing force - target quantity two - highlighted as (2) in Figure 5. Because when the sealing force is sufficient, the functionality can be assured.

Because the function describes the relation between input and output, the function has to be known to assure the functionality of the product. By knowing one of the quantities shown in Figure 5, the rest of the quantities, including the target quantity can be calculated by knowing the relation between input and output of the functions. For example in Figure 6 the reaction of the transferred mechanical energy $E_{\mathrm{M}}$ lead to a mechanical signal $S_{\mathrm{M}}$ that is changed by the actuator to a pneumatic signal $S_{\mathrm{P}}$. Because in reality these operations underlie disturbances like losses, the estimation of the desired quantity hast to consider those disturbances.

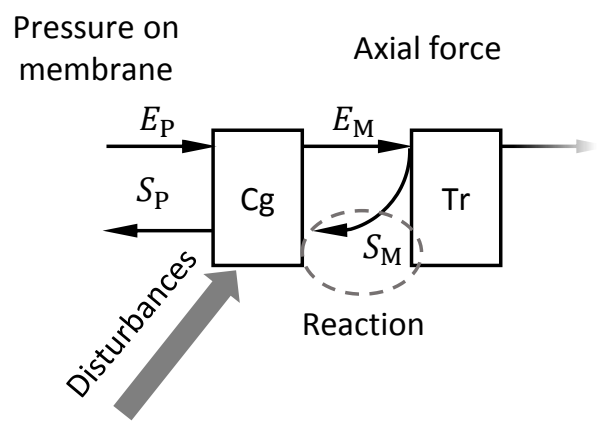

\section{Figure 6: Disturbances lead to uncertainty of the model based estimation of the target quantity.}

Because every operation in the function structure is resulting in disturbances and modelling effort, the total modelling effort can now be estimated by the number of operations between the target quantity and a potential measurable quantity in one of the components that realise the corresponding function. For this example, the possible components are already limited by the product structure. The remaining component actuator realises the function highlighted as (3) in Figure 5 and show, from the target quantity sealing force to the output quantity $E_{\mathrm{M}}$ four and to the input quantity $E_{\mathrm{P}}$ five operations. From the target quantity torque acting in the shaft, highlighted as (2) in Figure 5, the actuator shows one and two operations for the corresponding quantities $E_{\mathrm{M}}$ and $E_{\mathrm{P}}$. The remaining component shaft realises the 
function highlighted as (4) in Figure 5 and shows, from the target quantity sealing force to the output quantity two and to the input quantity three operations. From the target quantity torque acting in the shaft, highlighted as (2)in Figure 5, the shaft shows one and none operations for the corresponding quantities. The remaining component Housing cannot be represented in the function structure, because the reaction of the sealing force and acting torque are not a function, but a behaviour.

The number of operations cannot be taken for an absolute value, because the effort for modelling the behaviour of the functions differ for each function and depends also on the working principle. However, for a relative statement between measuring the input or output of the actuator lead to higher effort than measuring the in or output of the shaft. By including the knowledge of the working principle of the additional functions that have to be modelled, the decision between these two solutions is even clearer: The function of the transforming involves sliding friction and is highly depended on boundary conditions like lubrication, temperature and wear that can vary during the using life time of such a valve. Therefore, the further development of the actuator is rejected and the Housing and the shaft remain as possible solutions that have to be studied in more detail.

\subsection{Working space model as detailed evaluation of necessary modelling effort}

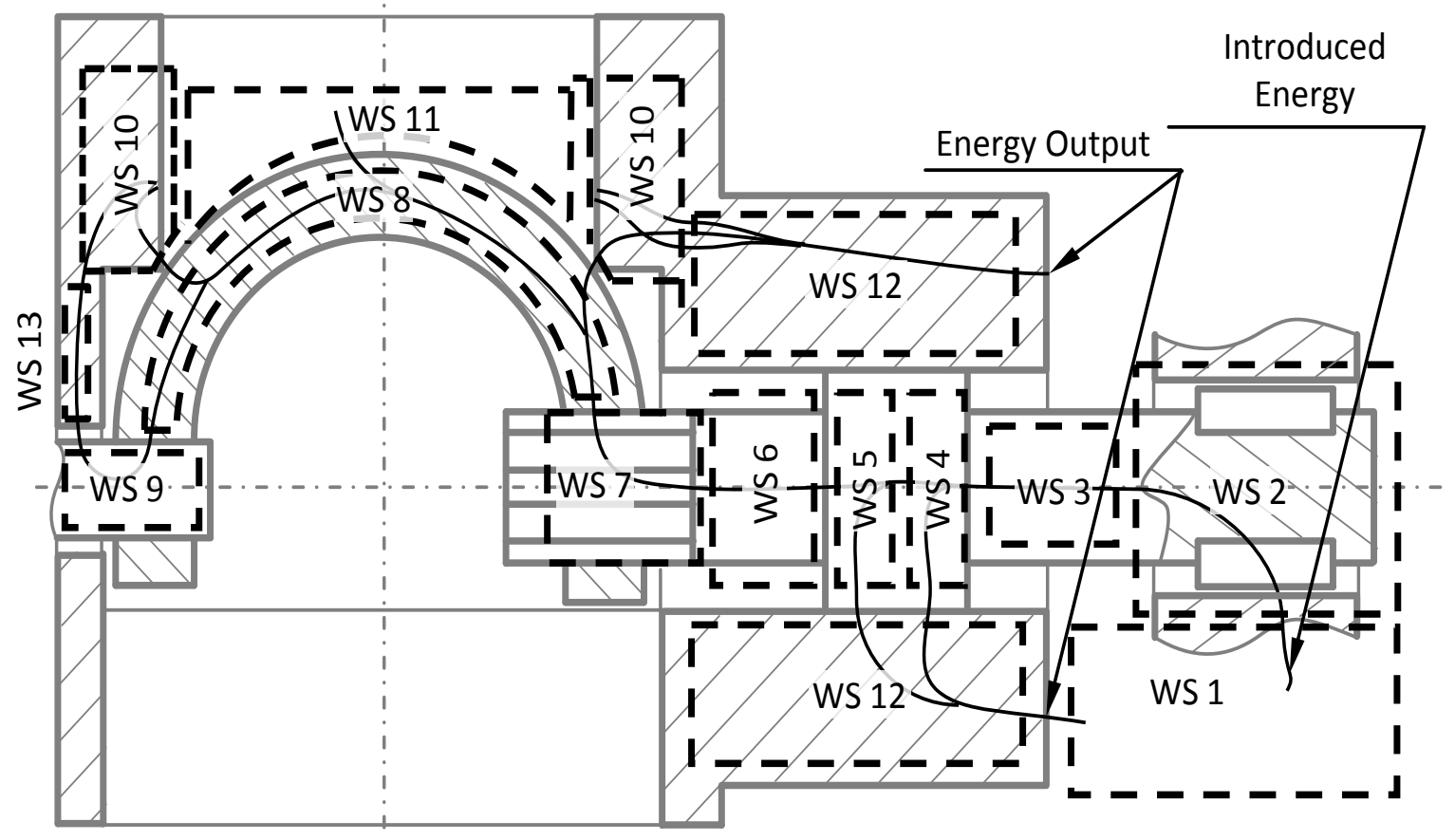

Figure 7: Flow of energy channelled through the working spaces of the rotary plug valve.

The Working Space Model is a model to help the designer to consider requirements in early design phases. It's original use is to describe intended and unintended flow of material and is presented in (Beetz et al., 2018). The Working Space Model can also be used to describe the flow of energy being exchanged between volumes by interaction of their contacts. In Figure 7 the rotary plug valve is pictured with the indicated Working Spaces for the state of a closed valve. In WS 1, energy is introduced, via the transmission by the actuator. The intended function is to channel the energy from the transmission or actuator to the sealing body, which is channelling the energy to the sealing seat. By analysing the Working Spaces it can be seen, in some Working Spaces the flow of energy is distributed and channelled in more bordering Working Spaces. For Example WS 5 and WS 4 show a junction of the flow of energy directly from the shaft into the housing. As in Chapter 4.2 already mentioned the flow of energy can also be flow of information when the reaction caused by the flow of energy is observed. In every Working Space the flow of energy is passing through, the energy can be derived by observing the properties that are influenced by the energy. For every junction of the flow of energy a model is needed, that has to take not only the observed value into account and results in a step of complexity and therefore a step of modelling effort - further called disturbances. The amount of distributions and deflections in a Working Space is a measure for complexity and effort. Simple possible solutions for the further development can now be identified by considering the Working Space Model and the flow of energy being channelled through the components of the existing system. 
For the example, depicted schematically in Figure 7, the target quantity torque acting on the shaft is still not specific enough. The torque that is acting on the shaft varies, due to torque introduction by form fit connection and friction over the length of the shaft and for monitoring the shaft, the torque and the bending moment in the most critical region is the more detailed target quantity. Because the most critical region in the shaft is not needed in this level of detail, the target quantity is defined as $T_{\text {Total }}$. Using the measurable quantity $T_{\text {Total }}$, by observing the property strain within WS 3 , the model results in the simple equation:

$$
T_{\text {Total }}=\left(G \cdot J_{\mathrm{T}} \cdot X\right)
$$

With $G$ as the shear modulus that is a material property, $J_{\mathrm{T}}$ as the polar moment of inertia that is a geometric property and $X$ as the observed property inside the Working Space, the shear strain on the surface of the shaft.

The model for determining the target quantity torque acting on shaft by measuring the combined part of the flow of energy in WS 12, because of the force and torque introductions, more complicated than (1) and need more testing and effort to reduce the uncertainty to an applicable level:

$$
T_{\mathrm{Total}}=T_{\mathrm{FRS}}+T_{\mathrm{Be} 2}+T_{\mathrm{Se}}+\ldots=f(X ; \mu ; E ; \text { Geometry; } \ldots)
$$

With $T_{\mathrm{FRS}}$ and $T_{\mathrm{Be} 2}$ being a function of the friction conditions in the bearing and the sealing, that can vary during the lifetime of the components. A relative comparison leads to the solution observing the property strain in WS 3 is the simpler solution. This comparison can be done for all possible solution to compare all solutions or until a solution acceptable simple is found.

With a Working Space found that is acceptable, the representative Working Space becomes the design space. This also guaranties the interfaces are kept and the changes in the functionality only happen inside a design space all possible interfering with the functionality of the product and the manufacturability are already known by the previous analyses.

\section{CONCLUSION}

The presented approach is a try to help product developer to reduce the complexity of integrating sensory functions in their existing systems. The sequence of the assessments is arbitrary and should be based on the requirement laid down on the gained information. For a simple integration of the additional functionality that is not justifying a radical change in the product structure, the structure should be taken into account first, because the risk of developing a solution that does not fit into the business case of the company is too high. The assessment with the function structure is more abstract than the one with Working Space Model and can help, when too many possible components are left to evaluate or not enough information for the assessment with the Working Space Model is known. The focus of the approach can be laid on the different assessments, to ensure a consideration of the individual boundary condition. The more modules are being considered for further development, the higher the effort to evaluate possible solution. Being too restrictive with possible module for further development can lead to complex behaviour and high modelling effort or to simple solutions, which are too simple to offer a useful benefit.

The ideal evaluation of the results of the assessments is object of further research to take different granularities and initial conditions into account. For comparing the results of the assessments, tools that make a relative information comparable like the FMEA can be the basis for taking a well-founded decision.

\section{REFERENCES}

Beetz, J.-P., Schlemmer, P.D., Kloberdanz, H. and Kirchner, E. (2018), "Using the new Working Space Model for the Development of Hygienic Products”, In: D. Marjanović, M. Štorga, S. Škec, N. Bojčetić and N. Pavković, (Ed.), Design 2018: Proceedings of the 15th International Design Conference, May 2018, Dubrovnik, Croatia, May, 21-24, 2018, Fac. of Mechanical Engineering and Naval Architecture Univ, Zagreb, pp. 985-996. http://doi.org/10.21278/IDC.2018.0142.

Brecher, C., Jasper, D. and Schmidt, M.F. (2016), "Methodik zur Ermittlung der Schraubenzusatzkräfte von Schraubenverbindungen", Konstruktion, Vol. 2016 No. 6, pp. 78-82. 
Foulard, S., Ichchou, M., Rinderknecht, S. and Perret-Liaudet, J. (2015), “Online and real-time monitoring system for remaining service life estimation of automotive transmissions - Application to a manual transmission", Mechatronics, Vol. 30, pp. 140-157. http://doi.org/10.1016/j.mechatronics.2015.06.013.

Greve, E. and Krause, D. (2018), “An Assessment of Methods to Support the Design of Future Robust Modular Product Architectures”, May, 21-24, 2018, Faculty of Mechanical Engineering and Naval Architecture, University of Zagreb, Croatia; The Design Society, Glasgow, UK, pp. 335-346. http://doi.org/10.21278/idc.2018.0249.

Groche, P. and Brenneis, M. (2014), "Manufacturing and use of novel sensoric fasteners for monitoring forming processes”, Measurement, Vol. 53, pp. 136-144. http://doi.org/10.1016/j.measurement.2014.03.042.

Groche, P., Calmano, S., Felber, T. and Schmitt, S.O. (2015), "Statistical analysis of a model based product property control for sheet bending”, Production Engineering, Vol. 9 No. 1, pp. 25-34. http://doi.org/10.1007/s11740-014-0576-5.

Krause, D. and Gebhardt, N. (2018), Methodische Entwicklung modularer Produktfamilien: Hohe Produktvielfalt beherrschbar entwickeln, Springer Vieweg, Berlin. http://doi.org/10.1007/978-3-662-53040-5.

Martin, G., Schork, S., Vogel, S. and Kirchner, E. (2018), "MME. Potentiale mikroinvasiver intelligenter Maschinenelemente", Konstruktion, Vol. 2018 No. 01-02, pp. 71-82.

Pahl, G., Beitz, W., Blessing, L., Feldhusen, J., Grote, K.-H. and Wallace, K. (Eds.) (2007), Engineering Design: A Systematic Approach, 3 Edition, Springer-Verlag London Limited, London. http://doi.org/10.1007/9781-84628-319-2.

Roth, K. (2000), Konstruieren mit Konstruktionskatalogen, Springer Berlin Heidelberg, Berlin, Heidelberg. http://doi.org/10.1007/978-3-642-17466-7.

Schaeffler Technologies AG \& Co. KG (2017), FAG VarioSense-Lager. konfigurierbare Sensorlager für die Maschinen- und Prozessüberwachung, Available at: https://www.schaeffler.de/content.schaeffler.de/de/news_medien/presse/pressemitteilungen/pressemitteilun gen_detail.jsp?id=76568131 (accessed 28 November 2018).

Schork, S., Gramlich, S. and Kirchner, E. (2016), "Entwicklung von Smart ME. Ansatz der smarten Ausgleichkupplung”, In: D. Krause, K. Paetzold and S. Wartzack, 2016, Design for X - Beiträge zum 27. DfX-Symposium Oktober 2016, Jesteburg, Germany, TuTech Verlag TuTech Innovation GmbH, Hamburg, pp. 181-192.

Stachowiak, H. (1973), Allgemeine Modelltheorie, Springer, Wien.

Vogel, S., Martin, G., Schirra, T. and Kirchner, E. (2018), "Robust Design for Mechatronic Machine Elements How Robust Design Enables the Application of Mechatronic Shaft-Hub Connection”, In: D. Marjanović, M. Štorga, S. Škec, N. Bojčetić and N. Pavković, (Ed.), Design 2018: Proceedings of the 15th International Design Conference, May 2018, Dubrovnik, Croatia, May, 21-24, 2018, Fac. of Mechanical Engineering and Naval Architecture Univ, Zagreb, pp. 3033-3040. http://doi.org/10.21278/idc.2018.0203.

Zhou, Z., Wang, Z. and Shao, L. (2016), "Fiber-Reinforced Polymer-Packaged Optical Fiber Bragg Grating Strain Sensors for Infrastructures under Harsh Environment", Journal of Sensors, Vol. 2016 No. 1, pp. 1-18. http://doi.org/10.1155/2016/3953750. 